\title{
Unamuno y el Sentimiento de la Inmortalidad
}

Como la mejor prueba de adhesión $y$ de elevado respeto a don Miguel de Unamuno, en los dias de su destierro, ATENEA inserta en su primer número este estudio sobre la obra más intensa del más grande de los pensadores españoles contemporáneos. $-\mathrm{N}$. de la D.

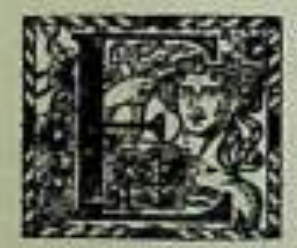

N la obra compleja de pensador, poeta y novelista de don Miguel de Unamuno, se advierte la presencia perenne de un motivo que parece constituir la razón de ser de su actividad intelectual y afectiva, el sentimiento de la inmortalidad. Y también de su olra actividad. de la que desarrolla como maestro y ciudadano, sobre todo de esta última, tan llena de viriles arrogancias y de gestos rebeldes que no es necesario recordar porque vivos están-de tal manera son recientes-en la memoria de todos. En -EL SENTIMIENTO TRAGICO DE LA VIDA. Unamuno analiza este sentimiento en sí mismo y en los demás, y lunda sobre èl una filosofia, una religión y una moral. Me propongo dar a conocer lo que el profesor salmantino llama sentimiento trágico de la vida, y la filosofía humanano cientifica-encaminada hacia la acción y el ideal que sobre este sentimiento ha concebido, filosolia más inclinada al lado de la poesía y del misticismo que al de la ciencia positiva, y la religión y la moral que de esta filosolia se infieren. Es una filosofia antiintelectualista, pragmática, vilalista, para emplear los términos técnicos con que se designa esta tendencia.

Visionario de la superación humana, busca un nuevo fundamento-fundamento inestable - a una filosofía que mira al ideal y al ensueño más que a la verdad puramente intelectual.

En todas las civilizaciones la aparición de la ciencia y de la filosofia, es decir. de una explicación racional de las cosas. ha traído como consecuencia un 
conflicto entre esta explicación y la que la religión, casi siempre de origen mucho más antiguo. contenía explicita o implícitamente. Los primeros pensadores racionalistas discuten los principios religiosos y dejan ver su carácter antirracional. La religión. nacida del instinto vital, obra de la inspiración o de la revelación, no cabe dentro de los rígidos moldes del razonamiento, desconocidos en la época de su génesis o desconocidos por sus fundadores. Asi vemos caer bajo la critica de Jenófanes y de los sofistas el politeísmo griego. El cristianismo se formó, Fuera de todo intelectualismo, de amor al ideal, de ansia de felicidad eterna, de principios morales. Apenas nacido se encontró con la cultura grecolatina, cullura intelectualisła y escéptica, propia de individuos refinados, de dialécticos sutiles $\sin \mathrm{fe}$ en el ideal, y tuvo que adaptarse a las fórmulas de la filosofía griega para poder prosperar en pueblos que necesitaban, además del sentimiento mistico, una explicación racional de las cosas. Desde entonces el sentimiento cristiano arrastra, como cosa postiza, una teologia racionalista.

La filosofia de la Edad Media fué una serie de ensayos para establecer la unidad y armonía entre la ciencia y la fe, y como sobre el espiritu cientifico de amor desinteresado a la verdad predominaba el sentimiento religioso, los filósolos hicieron prodigios dialécticos para alcanzar la fórmula del acuerdo entre la revelación divina y la especulación intelectual.

Durante el Renacimiento y en la Edad Moderna la ciencia y la filosolia se independizan de toda finalidad preconcebida, buscan la verdad por la verdad: la primera a base de experiencia elaborada por el razonamiento. la segunda a base de razón pura. Crean asi un cuerpo de docfrinas que se contradicen con ciertos principios religiosos.

Surge entonces en los espíritus cultivados, en el alma de los que se dedican a la ciencia y a la filosofia, un conflicto doloroso entre las conclusiones a que habian llegado por la vía puramente intelectual, impulsados sólo por el amor a la verdad, y los principios tradicionales de la religión, amoldados artificialmente a normas lógicas, porque tienen un origen qae queda fuera de lo intelectual, un origen vital, afectivo, el ansia de plena realización de nuestro yo en una vida ultraterrena,

La consecuencia de este confliclo son las transacciones que los pensadores han venido haciendo para no tener que renunciar a la razón al adherir al sentimiento. ni tener que renunciar al sentimiento al adherir a la razón. Las conclusiones de la razón son a menudo contrarias a lo que quiere el sentimiento. Honda tragedia encierran las palabras de Remy de Gourmont que Félix Le Dantec puso de epigrafe a su libro -El Ateismo: : Lo terrible que hay cuando se busca la verdad es que se la encuentras. Se encuentra la verdad que contradice nuestra creencia y mata en nosotros el sentimiento y el ensueño.

En la incapacidad de aceptar los principios de ninguna religión, los pensadores de la Edad Moderna sacaron del Cristianismo lo que les pareció la esencia de las aspiraciones religiosas. y fundaron lo que se llamó la religión natural: la existencia de Dios y la inmortalidad del alma. Consideraron estas dos creencias como inherentes a la naturaleza humana. Podia dejarse a un lado toda la 
teologia, podía prescindirse de los Evangelios, a cuya influencia durante siglos en el alma de los europeos se debía que estas creencias llegaran a parecer naturales, pero lo esencial se conservaba: la creencia en la inmortalidad y en la existencia de Dios que la garantiza. las únicas creencias capaces de safisfacer el ansia de inmortalidad. A pesar de su abstracción, de su carácter friamente racional. esta fórmula de la religión natural obedece al sentimiento de la inmortalidad, que constituye la esencia de la religión tal como la concibe un pueblo de cultura superior.

Pero la creencia en la inmortalidad personal. algo que parecia muy de acuerdo con la razón aunque filósofos aislados la hubiesen negado. fué haciéndose cada vez más difícil de sostener dentro de un criterio puramente científico. y algunos espíritus llegaron a la conclusión de que no había base para sostenerla dentro del campo de lo puramente intelectual. La religión se venía entonces al suelo: había qce vivir la vida y resignarse a dormir por toda una eternidad, digo mal, dormir no, porque el que duerme sueña y soñar es existir. era necesario resignarse al eferno no ser, al aniquilamiento total del yo. de este yo nuestro que sentimos como una realidad inmediata mientras vivimos. Los que asi pensaban eran hombres de un profundo espíritu religioso. hombres para los cuales era terrible. como dice Gourmont, haber llegado a tales conclusiones. Inventaron entonces remedos de religiones para satisfacer la inquietud sentimental de las almas que sentian el vacio de la pérdida de la fe en la inmortalidad. Entre estos ensayos que yo llamaria de desviación del sentimiento religioso-ya que éste una vez concebida la inmortalidad personal tiende necesariamente hacia ella como hacia la suprema aspiración humana-pueden cilarse los de Comte. Spencer y Haeckel.

Sabido es que para Comte no hay sino una forma del conocimiento que quede fuera de la ilusión y del ensueño: el conocimiento positivo. es decir. el conocimiento fundado en la experiencia y elaborado por la razón. La metalísica y la teologia son especulaciones absurdas, carecen de fundamento. La filosofia debe limitarse a unificar los conocimientos elaborados por las ciencias. Pero la sociedad humana, a cuyo progreso debemos el que hayamos llegado a elaborar la ciencia, ha sido organizada sobre la base de la religión: sólo el sentimiento es capaz de engendrar. Para regenerar la sociedad y darle una nueva vida hay que regenerar la religión. eliminando los elementos caducos de las religiones tradicionales y conservando el elemento positivo que encierran. Así se pasa de la filosofía positiva a la religión positiva. La necesidad que siente el hombre de creerse inmortal y de creer en un Dios que es garantía de esta inmortalidad y de la participación de los justos en el reino de Dios, no puede satisfacerse dentro del criterio positivo con estes creencias, ambas de carácter mefalísico y por consiguiente ilusorias, sino con algo que está mucho más cerca de nosotros. en nosotros mismos: la humanidad.

El amor sexual engendra el amor a la familia: el amor a la familia engendra el amor a la patria: y el amor a la patria, el amor a la humanidad. La humanidad en cuanto es objeto de la forma suprema de nuestro amor. se con- 
vierte para nosotros en el Gran Ser, en Dios que vive en nosotros, dirige nuestros actos y nos hace pasar del egoísmo al altruismo.

Más filosófica y menos concreta es la solución de Herbert Spencer. Hay en el fondo y en el origen de todas las cosas algo incognoscible. Lo incognoscible es lo absoluto. Lo absoluto, Dios, es inaccesible a nuestra inteligencia. Lo incognoscible de Spencer es una idea de residuo, una idea negativa.

Haeckel dice que hay que concluir con los dogmatismos metafisicos y teológicos, y fundar una filosolía cientifica sobre la base de dos grandes principios: el monismo y el evolucionismo. Sólo hay un ser, una substancia, que se presenta bajo formas diversas de grado o cantidad y está en constante cambio. sometido a leyes inmutables. El hombre es sólo un eslabón en la cadena de las cosas, un fenómeno de la substancia única. El dogma de la inmortalidad es absurdo: la religión es ilusoria. La única fuente de conocimiento es la experiencia y el razonamiento que unidos constituyen la razón. Para satisfacer las necesidades afectivas que llenaban las religiones tradicionales, crea el culto de una nueva Trinidad: lo verdadero, lo bueno y lo bello. La religión monista se opone radicalmente al cristianismo en su concepción de lo verdadero y de lo bello. pero coincide casi totalmente con él en su concepción del bien. Este punto de contacto entre la religión tradicional y la nueva fe, sirve de lazo de unión entre ambas y facilita el paso de una a otra.

Esta ha sido la doctrina que más influencia ha ejercido entre los hombres de ciencia en el curso del siglo pasado.

En estos sistemas predomina en absoluto la ciencia sobre el sentimiento religioso. Se trata de satisfacer este sentimiento con un remedo de religión hacia el cual se le desvía.

Otros pensadores en los cuales el sentimiento religioso es muy vivo, buscan una transacción que les permita colocar la religión en un dominio aparte. fuera del campo de lo puramente intelectual. A este grupo pertenece el propio Unamuno y son sus más notables precursores Ritschl y James.

Ritschl sostiene que la religión sólo puede realizarse plenamente _si se la purifica de todo lo que no es religión, pero debe contener todo lo que necesita para desarrollarse y alcanzar su plenifud. Para conseguir esto hay que dejar a un lado la filosofia, la teología: hay que romper con el intelectualismo. La facultad de conocer sólo puede abarcar las leyes referentes al mundo fisico. Lo religioso, to puramente espiritual, queda fuera de su dominio. La religión se cree. no se conoce.

Hay que despojarla además de la autoridad propia del Catolicismo: para el cristiano no hay ni puede haber otro maestro que Jesucristo. El Evangelio es verdadero, no porque esté de acuerdo con ésta o aquélla realidad, sino porque en el seno de nuestra conciencia lo juzgamos digno de ser verdadero. Así independiza Ritschl al mismo tiempo la religión de la vieja teología y de los avances de la ciencia positiva. Y como la contradicción atormentadora de los espíritus era más que todo una contradicción entre la teología y la ciencia. 
abandonada la teología por inútil y separados radicalmente los dos campos, el de la ciencia y el de la religión. ambas pueden prosperar libremente y alcanzar su plenitud.

En Dios encuentra la conciencia religiosa la explicación de las impresiones religiosas que el orden natural no explica. Así asegura Ritschl en el seno del alma el desarrollo de la vida religiosa que queda fuera del alcance de toda ciencia.

Herrmann, discípulo de Ritschl, distingue el fundamento y el contenido de la fe. El fundamento es aquella parte de la revelación que se necesita exponer para que ésta sea experimentada por toda alma sensible y sincera. El contenido especial de la le representa una experiencia más determinada que varía de individuo a individuo. La consideración de la vida interior de Jesús hace creer naturalmente en Jesús: éste es el fundamento de la le. Todos los demás detalles en que cree el individuo son el contenido de la fe. El fundamento constituye la esencia de la fe: el contenido, lo accidental.

Ritschl independiza totalmente la religión de lo intelectual. El hombre siente directamente la acción de Dios, el cual queda fuera del campo del conocimiento. Es sólo un objeto al cual se aspira, y puede ser una ilusión subjetiva.

Los pragmatistas afirman que la ciencia, además de ser un producto de la actividad del espiritu que crea símbolos para explicarse las cosas, está orientada hacia la acción. tiene en la acción su único objeto.

De esta concepción de la ciencia surge un nuevo concepto de la verdad: no es el acuerdo entre ciertos juicios formulados y tal o cual realidad que se da de antemano. sino el servicio que puede prestarnos para alcanzar tal o cual resultado. Verdad quiere decir verificabilidad, y verificabilidad significa aptitud para guiarnos en la experiencia. El porvenir no está predeterminado: lo verdadero es lo que está pronto a ser. El porvenir es creado por sus causas, entre las cuales se encuentra la ciencia libre y humana que impone a la naturaleza efectos que ella sola no habría alcanzado jamás. La creencia es un factor de esta realización. La fe puede crear su propia verificación experimental y llegar a ser verdad por su acción misma. El ser, objeto de la ciencia, no es una cosa hecha para toda la eternidad; se hace constantemente por la acción de los seres y en particular por la acción humana apoyada en la ciencia y en la creencia. Creencia verdadera es la verificable, la bienhechora, la eficaz.

La ciencia no es obra de la naturaleza; es el producto de la actividad intelectual del hombre. Introducimos por medio de ella unidad, continuidad y simplicidad en el mundo y lo hacemos asi inteligible. Los fines que la ciencia persigue son leyes que el espiritu impone a las cosas.

El hombre es, antes que inteligencia, acción. La acción persigue un fin. La acción revela al hombre que hay en el mundo una voluntad inicial.

La actividad humana tiene dos formas esenciales: la inteligencia y la voluntad. La ciencia es la realización de la primera y la religión de la segunda. La ciencia da al hombre medios de acción exteriores. El hombre se pregunta también sobre su principio y sobre su fin. La religión es una sabiduría suderior que 
señala al hombre un fin digno y la potencia necesaria para querer eficazmente ese fin.

La ciencia y la religión son dos momentos diversos de nuestra actividad. La ciencia significa expansión de nuestro yo al exterior; la religión significa esa misma actividad vuelta hacia adentro, donde está el principio de toda vida. Entre una y otra no hay contradicción posible.

para William James, como para los místicos, la experiencia religiosa está constituida por objetos perceptibles inmediatamente, en forma análoga a los datos del mundo físico que sirven de material al investigador experimental.

La verdad de la religión es afirmada en seguida pragmáticamente, por sus resultados. La religión es algo subjetivo individual, algo que cada cual afirma por su propia experiencia interna. Lo esencial es Dios. James establece la posibilidad de la inmortalidad del alma, pero no la considera esencial. Considera que. concluida la labor de cada cual. labor divina porque a la realización de Dios se encamina, bien puede el hombre resignarse a dejar de ser.

En estos sistemas se encuentran los antecedentes lógicos de las doctrinas del pensador español. Los antecedentes psicológicos se encuentran expuestos en la obra de Unamuno, el cual considera que el estudio de una doctrina debe hacerse asi. por el estudio del hombre y no por las doctrinas de los pensadores anteriores. Sin embargo no puede negarse el nexo que hay entre dos concepciones sucesivas del mundo y de la vida. El antecedente histórico, lógico. se une al psicológico para determinar la aparición de una doctrina metafisica o religiosa. Si no es aceptable eliminar los antecedentes causales al explicar la aparición de una hipótesis para limitarse a dar a conocer su razón lógica, es evidente que el antecedente lógico o razón. que forma parte de los antecedentes causales, no puede ni debe ser eliminado, si se quiere dar a conocer la causa total de la aparición de la doctrina. Esto hay que criticar pero sólo teóricamente a Unamuno, porque él, prácticamente y en razón de que una de sus tesis así lo exige, da a conocer los antecedentes de su posición en actitudes análogas de filósofos y poetas. No cabe duda sin embargo de que el elemento causal preponderante en la actitud filosófica es el complejo psicológico que se designa temperamento. Unamuno da a conocer con sinceridad y emoción el proceso de la formación de su doctrina metafísica, religiosa y moral sobre la base de un sentimiento. Desde el punto de vista psicológico su obra es un documento precioso para estudiar el ecaso Unamuno., la trágica lucha entre el racionalismo moderno y el misticismo católico hereditario en el seno de una conciencia de vida afectiva muy rica y sutil para el razonamiento, algo análogo al caso Chesterton que puede estudiarse en Ortodoxia, a pesar de la disparidad de las conclusiones.

He aqui la doctrina expuesta en forma genética o psicológica, siguiendo el método del autor, en oposición a la forma lógica o sistemática que es la generalmente seguida. 
Hay que cambiar el método de estudiar a los filósofos. No se trala ya de derivar sistemas de sistemas, como se hace en los tratados de filosofia, sino de estudiar cada sistema con relación a psicología de su fundador: porque la filosofia es la manera que tiene cada cual de comprender el mundo y la vida, y esa manera tiene como raigambre el sentimiento que de la vida tengamos. Así, la filosolia de Kant se aclara si se considera que la reconstrucción metafísica hecha por este filósolo en la Crítica de la Razón Práctica, obedece a una necesidad afectiva, la de sentirse inmortal. La Crítica de la Razón Práctica es la justificación de la aspiración suprema de inmortalidad del luterano Manuel Kant.

Benito Spinoza, el racionalista implacable de que hablan los tratados de filosofia, se humaniza mirado desde este punto de vista unamuniano. Y asi otros.

Hay que analizar el sentimiento, no el conceplo, de la propia personalidad. del yo concreto y personal, de ese algo que no queremos dejar de ser aunque estemos muy descontentos de nosotros mismos. Nadie que sienta realmente su propio yo, su propia personalidad, quiere ser otro yo. Su yo es para cada cual su universo. lo único que en primer término le interesa. Si eliminamos nuestro yo, no podemos concebir nada ni tenemos para que concebir nada. La noción del yo es la noción primaria sin la cual-causa primera de todas las demásse hacen estas ociosas o son inconcebibles.

Esta noción del yo que quiere superar a la muerte se nos impone por sí misma. es en el fondo más sentimiento que idea-este carácter afectivo es lo que le da su fuerza-y contra los valores afectivos nada puede la razón. Para que una filosofia sea algo más que una nomenclatura técnica, debe aspirar a conciliar las necesidades infelectuales con las afectivas y volitivas. Este es el problema trágico que a todo filósofo se presenta, el que no pudo resolver Spinoza esclavizado por su intelectualismo, el que resolvió Kant contradiciendo en su filosofía práctica lo que había sostenido en la teórica.

Unamuno rechaza las desviaciones del sentimiento de la inmortalidad, aquellas de que hablamos anteriormente, fundándose en el carácter único de la noción del yo que no admite substitutos. Aqui se separa francamente de James que da a la inmortalidad un valor secundario. Para Unamuno es lo fundamental y en ella está la raíz de toda filosolia y de toda religión.

Este deseo do perdurar. esta ansia de no morirnos que nos hace creer en la supervivencia del espiritu, es lo que Unamuno llama sentimiento trágico de la vida. Este sentimiento implica una filosolia más o menos formulada. una concepción del mundo y de la vida, y tiene manifestaciones en la psicología de las colectividades.

Hay una necesidad de conocer para procurarse alimento y precaverse de lo que es perjudicial a la vida que nos es común con los animales, y hay un deseo 
de conocer propio sólo del hombre. un conocimiento reflexivo, consciente, producto posterior del desarrollo social y del lenguaje.

El instinto de la conservación individual nos revela la existencia del mundo exterior. Debe haber un mundo ideal, hijo del amor, del instinto de perpetuarse. fundamento de las sociedades humanas. Y tanto se puede decir que es creación nuestra, obra de nuestra fantasia este último, que el otro mero producto de nuesfros sentidos. Esta facultad intima, imaginativa, nos revela la existencia de Dios.

Cada filosofia es un producto humano: el filósofo quiere filosolar sólo con la razón, pero filosofa también con la voluntad y el sentimiento. Tenemos siempre en vista un fin práctico: buscar finalidad a la vida. resignarse a vivirla, efc.

Lo más hondamente humano es la finalidad, el para qué. Si buscamos con ahinco el por qué es para mejor comprender el para qué. Lo que Spinoza llamaba la esencia de la cosa, el conato que pone en perseverar en su ser indelinidamente, el ansia humana de inmortalidad, puede ser la condición primera de todo conocimiento reflexivo y puede por lo tanto ser la verdadera base de toda filosofia. descuidada por los filósofos a quienes el intelectualismo perturba.

Conocemos para eternizarnos, conocemos porque está vivo en nosolros el deseo de alcanzar la eternidad. Este problema afectivo es probablemente irresoluble y la renuncia desesperada de resorverlo puede constituir la solución. El sentimiento trágico de la vida es el punto de partida de toda filosofia humana -no técnica-y de toda religión.

Hay que analizar esta ansia de inmorlalidad. No podemos concebirnos inexistentes. Se nos hace estrecho el mundo sensible revelado por el instinto de conservación y queremos alcanzar lo ilimitado del espacio y la eternidad del tiempo.

El fluir de la vida ha arrancado gritos de las entrañas a los poetas que han sentido más hondamente que los demás hombres esta hambre de eternidad. El pensamiento de la muerte y del misterio del más allá son el slatir mismo de la conciencia. El culto de la muerte es el origen de todas las religiones: el hombre es el único animal que conserva sus muertos. Construyó primero monumentos funerarios capaces de resistir a las edades que residencias duraderas para los vivos. La meditación sobre la muerte, congojosa al principio, se hace después reconfortante. Si no hay supervivencia después de la muerte el mundo es una sucesión de fantasmas; la nada es más terrible que el infierno católico. El hambre de eternidad nos amarga la vida. Este es el problema trágico, el único verdadero problema de la vida humana.

La razón prueba que el alma no es inmortal; la razón es incapaz de volver la calma al corazón. A ella opone Unamuno la afirmación de su deseo: ‘No quiero morirme, no, no quiero ni quiero quererlo: quiero vivir siempre. siempre. siempre, y vivir yo, este pobre yo que me soy y me siento ser ahora y aqui.. (1) A falta de fundamento racional hay que fundar la 'creencia en la inmortali-

(1) El sentimiento trágico de la vida. pág. 48. 
dad sobre el deseo de inmortalidad. Trágico hado, sin duda, el de tener que cimentar en la movediza y deleznable piedra del deseo de inmorlalidad la afirmación de ésta: pero torpeza grande condenar el anhelo por creer probado, sin probarlo, que no sea conseguidero. ¿Qué sucño...? Dejadme soñar, si ese sueño es mi vida no me despertéis de él. Creo en el inmortal origen de este anhelo de inmortalidad, que es la substancia misma de mi alma, (2). Este arrebato lírico muestra claramente el estado de alma del filósolo-¿filósofo o poeta?que siente la tragedia entre el deseo que afirma y la razón que niega.

Los hombres, cuando dudan de la inmortalidad, quieren alcanzar siquiera una forma aparencial de ella. la supervivencia en la memoria de las sociedades humanas. Otros logran saciar la sed de inmortalidad con la fe religiosa cátólica. - el fin primordial del Catolicismo es conservar la fe en la inmortalidad-pero esta religión ha racionalizado la fe $\mathrm{y}$, al racionalizar lo que es confrarracional por naturaleza, se ha puesto en conflicto con la propia razón. La solución cristiana y sobre todo la católica satisface a la voluntad, a la vida, pero no satisface-debido al racionalismo contrarracional de su teología-a la razón. la cual a su vez tiene exigencias imperiosas. El hombre que ha alcanzado su plenifud racional, por vivo que sea en él el sentimiento religioso, no puede aceptar que se le presente como racional lo que no lo es.

Si para satisfacer plenamente las necesidades racionales se busca la solución en la filosofia tampoco se la encuentra. No se puede probar racionalmente la inmortalidad del alma. En cambio puede probarse su mortalidad con un grado muy alto de certeza. El monismo, aunque sea idealista, no salva la inmortalidad. Para nuestro anhelo vital da lo mismo decir que todo es materia o que fodo es idea. La inmortalidad sólo se salva con la doctrina de la dualidad substancial: materia y espiritu. La razón, monista por naturaleza,-tendemos fatalmente a la unidad-no necesita para nada de la hipótesis de la substancialidad del alma. Esta hipótesis, racional en apariencia, es una creencia fundada en nuestro anhelo vital de perdurar eternamente.

Unamuno buscó la prueba de la inmortalidad en las investigaciones psiquicas de los espiritistas. No encontró la justificación de su anhelo. Tampoco la encontró en el panteísmo ni en el agnosticismo de Spencer. La razón es la enemiga de la vida, se pone en contra de nuestro anhelo. La vida es inestable, individual, fluye: la razón. a quien la vida se le escapa, busca la muerte. equiere cuajar en témpanos la corriente fugitivas. La razón es incapaz de comprender la vida y el anhelo vital que es su carácter esencial. Es un combate trágico el que se desarrolla en nosotros entre la razón y la vida. El autor acude a expresiones lógicas porque es el único medio de hacerse entender. pero no emplea el método racional.

Los creyentes tratan de engañarse con los argumentos gastados de la teologia para seguir viviendo, y los racionalistas incrédulos tratan de buscarle a la

(2) El senfimiento trägico de la vida, pág. 51. 
vida otra finalidad. Estas soluciones le parecen vacias e hipócritas. Es mejor confesar que la razón es una potencia desconsoladora y disolvente.

No es posible desentenderse del enorme misterio del Universo y de nuestros destinos. Este problema que una vez formulado no se borra más del espíritu, es el problema vital por excelencia, y no podemos honradamente desentendernos de él.

El sentimiento no logra hacer verdad del consuelo religioso contenido en el Catolicismo: la razón por su parte, dada la vaciedad de las doctrinas religiosas de un Haeckel o de un Spencer, no puede hacer de la verdad consuelo. La razón conduce, en último término, al escepticismo y en el fondo del abismo a que nos lleva encuéntrase con la desesperación sentimental y es de este encuentro de donde surge una base de solución del conflicto. Alli se dan ambos un abrazo trágico del cual ebrota un manantial de vida seria y terribles.

La desesperación del sentimiento vital funda su esperanza sobre la incertidumbre acerca de su propia validez que es la posición última a que llega la razón cuando se analiza a si misma.

Cuando cree llegada la hora de las afirmaciones, advierte al lector que podia encontrarse seducido por su ardor lírico, por el sentimiento religioso y por la sinceridad de sus confesiones. con crudeza, que no se engaña ni pretende engañar: sus especulaciones carecen de valor intelectual. ITerrible sinceridad que no le permite engañarse cuando sería más reconfortante sentirse cogido entre las redes de la ilusión!

Se coloca definitivamente fuera de la razón. Va a hablar en nombre de la vida y va a coincidir con otros hombres que han revelado también su vida intcrior.

Esta posición puede ser fuente de esperanza, de acción, de progreso. Con esto queda justificada pragmáticamente. No quiere justificación alguna: su posición es un hecho y eso besta. Se resigna a que sus doctrinas sean consideradas como un documento psicológico en que se podría estudiar la crisis de un alma donde luchan el racionalismo científico y el sentimiento místico, ambos desarrollados plenamente y radicalmente incompatibles.

Las doctrinas que expone en seguida han sido engendradas por su anhelo vital. La verdad de los lógicos, la que no tiene ningún fundamento afectivo. se escapa igualmente a los que creen poder alcanzarla y a los que no lo creen.

Del amor entre hombre y mujer para perpetuar el linaje humano, nace el amor espiritual y doloroso. El primero es engendrado por el placer y el segundo por el dolor. El amor espiritual es compasión, compasión de sí mismo y de todo lo que, como nosotros, es y dejará de ser. Asi se llega al tedio de la existen- 
cia. El amor personaliza todo lo que ama; cuąndo ama el todo, personaliza el todo y surge la idea de Dios en el espírifu. Personalizamos el todo para salvarnos de la nada, y lo hacemos infinito, eterno, perfecto, como nosotros anhelamos ser. En el flujo y reflujo de la historia del pensamiento humano, el concepto de Dios nace y vuelve a nacer, porque la vida, vencida momentâneamente por la razón, vuelve a engendrarlo.

Hay una fuerza oculta, intima. esencial, que mueve a los organismos a conservarse o, a ser. a perpetuarse. Podemos llamar a ese impulso voluntad. Es un impulso a serlo todo sin dejar de ser lo que somos. Esta fuerza es lo divino que hay en nosotros. es Dios mismo que obra en nosotros porque en nosotros sufre. Todos los seres se sienten agitados por una fuerza que los mueve hacia la conciencia.

La creencia en un Dios espiritual y personal se funda en la creencia en nuestra propia personalidad y espiritualidad. El fundamento de la creencia está en el amor, en nuestro anhelo vital que así se safisface. Sólo así se da finalidad al Universo y al hombre. Nuestro anhelo crea a Dios constantemente en nosotros. Así salvamos al Universo de la nada y nos salvamos nosotros mismos. porque sólo lo que es conciencia existe; lo demás es apariencia. Dodemos pensar la existencia sin Dios: no podemos vivirla. Podemos averiguar el cómo y el por qué de la existencia sin Dios: no podemos sin él sentir para qué es.

El sentimiento religioso es sobre todo sentimiento de la divinidad. El sentimiento de la divinidad nace del sentimiento de nuestra personalidad proyectado aluera. Y este sentimiento da origen al concepto. Primero existió el Dios religioso. humano, producto de la conciencia colectiva de un pueblo. Después se apoderó de él la filosofía y creó el concepto lógico. definido. el ser supremo. primer motor de la filosofía teológica, un ente racional sin vida. Este Dios lógico. racional, en que el concepto de necesidad substituye al de divinidad, en que desaparece la voluntad de Dios, el elemento primario de su personalidad, no es el Dios capaz de satisfacer nuestro anhelo vital. de salvarnos de la muerte. El Dios inmortalizador tiene que ser un Dios arbitrario ante la razón, porque la razón no es el camino que a él conduce, sino el amor y el sufrimiento. Quien le ame, quien tenga verdadera hambre de él. lo sentirá. y al sentirlo tendrá conciencia de él por experiencia direcla. Este sentimiento directo de Dios y el sentimiento trágico de la vida son ambos sentimientos de hambre de Dios, de carencia de Dios. Y en esta hambre está la gran tragedia de la vida. El escepticismo racional y la desesperación sentimental le encendieron el hambre de Dios. Al sentir su Calta se dió cuenta de su realidad.

El Dios de la razón es una razón suprema, en el mismo sentido en que la ley de la gravitación universal es razón de la caída de los cuerpos. Es impersonal, incapaz de amar y de ser amado. El vitalismo lo concibe como conciencia, como persona capaz de amar y ser amada. El Dios del racionalismo se 
destruye a si mismo en cuanto Dios. El Dios humano satisface nuestra ansia de inmortalidad. La razón debe aplicarse sólo al mundo exterior: si sube más arriba es nihilista, aniquiladora. En esas regiones hay que dejar libre a la imaginación capaz de darnos vida ilimitada, intuición del mundo espiritual. El Dios humano no es un concepto lógico y no es susceptible de ser definido; se le siente, no se le conoce. La existencia de este Dios no se puede probar racionalmente. La angustia vital nos lleva a creer en él. Se llega a Dios por el camino de la fe y no por el de la convicción racional.

La fe se presenta como conocimiento, como juicio, pero es en el fondo afectiva. La fe verdadera es fe a base de incertidumbre. La fe nos hace vivir mostrándonos que la vida, aunque dependa de la razón, tiene en otra parte su mananfial, en algo sobrenatural y maravilloso. La fe es la voluntad misma de no morir. La fe, en cierto sentido crea su objeto. Creamos a Dios por la fe, y como Dios nos da la fe que en él tenemos, es Dios quien se crea de continuo en nosotros. Sin amor o femor no hay verdadera creencia en Dios; lo demás es creer en la idea de Dios, algo impersonal. Para un intelectual. en el estado actual del conocimiento, creer en Dios no puede ser más que querer que Dios exista y conducirse y sentir como si existiera. Dios sale al encuentro de quien le busca con amor y por amor, y se hurta de quien le busca por fria razón no amorosa. (1).

$\mathrm{Y}$ en seguida agrega: ¿Y si se me preguntara cómo creo en Dios, es decir. cómo Dios se crea en mi mismo y se me revela, fendré acaso que hacer sonreir, reir o escandalizarse tal vez al que se lo diga.

Creo en Dios como creo en mis amigos, por sentir el aliento de su cariño y su mano invisible e intangible que me trae y me lleva y me estruja, por tener intima conciencia de una providencia particular y de una mente universal que me traza mi propio destino. Y el concepto de la ley-iconcepto al cabol-nada me dice ni me enseña.

Una y otra vez durante mi vida heme visto en trance de suspensión sobre el abismo: una y otra vez heme encontrado sobre encrucijadas en que se me abria un haz de senderos, tomando uno de los cuales renunciaba a los demás, pues que los caminos de la vida son irrevertibles. y una y otra vez en fales únicos momentos he sentido el empuje de una fuerza consciente, soberana y amorosa. Y ábresele a uno luego la senda del Señor.

Puede uno sentir que el Universo le llama y le guía como una persona a ofra. oír en su interior su voz sin palabras que le dice: iVe y predica a los pueblos todos! ¿Cómo sabéis que un hombre que se os está delante tiene una conciencia como vosotros. y que también la tiene. más o menos obscura, un animal y no una piedra? Por la manera como el hombrc, a modo de hombre, a vuestra semejanza se conduce con vosotros, y la manera como la piedra no se conduce para con vosotros, sino que sufre vuestra conducta. Pues así es como

(1) El sentimiento trägico. pâg. 193. 
creo que el Universo tiene una cierta conciencia como yo. por la manera como se conduce conmigo humanamente, y siento que una personalidad me envuelve. ( 1 ).

El Dios vivo se nos revela por el sufrimiento. Los hombres hicieron Dios a Jesucristo y descubrieron por él la eterna esencia de un Dios vivo, humano. El primer motor, la idea filosófica de Dios, permanece inmutable, no sufre. El dolor es la substancia de la vida; los seres vivos formamos la gran hermandad del dolor.

La conciencia universal está limitada por la materia bruta en que vive. Trata de libertarse y de libertarnos y por eso sufre. Una formidable corriente de dolor impulsa a los hombres unos hacia otros y los hace buscarse, unirse. El individuo. movido por el instinto de conservación creador del mundo material, tendería a la destrucción si no fuese por la sociedad que. dándole el instinto de perpetuarse, creador del mundo espiritual, lo lleva a inmortalizarse.

Lo que el individuo hace como tal. frente a la sociedad es malo; es bueno lo que hace como persona social dentro de la sociedad para perpetuarse y perpetuarla. El que hace servir el ideal a sus intereses materiales o a su gloria en lugar de servir él al ideal, crucifica a Dios.

El sentimiento de Dios y la fe y la esperanza y la caridad que en él se fundan, dan origen a la religión que es la relación entre el alma y Dios.

No le parecen aceptables las doctrinas católicas sobre las penas de ultratumba; le parece más aceptable pensar que se salvan los que anhelan salvarse. Se eternizan los que vivieron sufriendo de hambre de eternidad. Y los que no. vuelven al seno de la inconciencia.

No quiere la gloria como una quieła contemplación de Dios sino como un eferno acercarse sin llegar nunca, una esperanza eterna renovada eternamente. Asi la sueña, asi la desea, y podría ser este deseo la revelación de una verdad inefable, ultrarracional. Cada vez que queremos dar forma racional al anhelo caemos en contradicciones; pero hay que seguir anhelando para vivir, no para comprender.

Ante esta contradicción entre el anhelo vital y la razón no cabe más que una actifud: afirmar los contrarios, vivir en contradicción, afirmar una cosa con la cabeza y otra con el corazón, y hacer de este estado de contradicción la esencia de nuestra vida.

Esta actitud es aparentemente insostenible. La apasionada incertidumbre a que da lugar da unidad y razón práctica de ser a la vida. Sobre ella se puede fundar una moral.

El que basa su moral en un dogma corre el peligro de que, vacilando el (1) El sentimiento trágico, póg. 195. 
dogma, vacile tambiēn la moral. El que no tiene dogma, sino incertidumbre, obra, no porque crea verdadero su principio de acción. sino porque aspira a hacerlo tal, a crearse su mundo espiritual. La conducta prueba la doctrina. El aspira a hacer de su vida una comprobación de su doctrina (1).

Nuestra verdad cordial y antirracional, la inmortalidad del alma, encuentra su prueba moral en la realización de este principio ético: .Obra de modo que merezcas a fu propio juicio y al juicio de los demás la inmortalidad, que te hagas insubstituible, que no merezcas morir. También puede formularse asi: .Obra como si hubieras de morirte mañana, pero para sobrevivir y eternizarte.

Si la inmortalidad resulta una ilusión. que nuestro aniquilamiento sea una injusticia. como pensó Sénancour.

El sentimiento de hacernos insubstituibles debe llevarnos a cumplir con apasionamiento trágico nuestro deber. Hay que tratar de sellar todas las cosas con el sello de nuestra personalidad.

Los viejos mandamientos de Moisés, los negativos, deben ser cambiados por otros de carácter positivo. Así, en lugar de ino mentirásl éste: idirás siempre la verdad oportunamente o nol En lugar de Ino matarás! jacrecentarás y darás vidal En lugar de ino hurtarás! lacrecentarás la riqueza pública!

Para concluir afirma que lo que él llama sentimiento trágico de la vida es. por lo menos. el sentimiento trágico de la vida del pueblo español reflejado en su alma que se engendró en España.

Hemos seguido, lector, casi paso a paso, el pensamiento ondulante. tortuoso. del pensador de Salamanca, traducido en un estilo que sigue el fluir espontáneo de la vida psíquica, adaptándose a la corriente vifal del pensamiento. estilo que él prefiere siempre al ordenado, al lógico, en que el pensamiento corre por cauces hechos de antemano con rigorismo intelectual. $\mathrm{Y}$ esto es, además de su contenido, lo que hace de las disquisiciones del ilustre pensador una obra de interés emocional, humano, literario en el noble sentido de esta palabra. El sentimiento trágico de la vida. puede ser interpretado como un poema. el de la tragedia interior de un alma atormentada por la sed de eternidad. e incapaz de adherir a la creencia en la inmortalidad con la sencillez del creyente. por la clara visión de las dificultades racionales que a esa creencia se oponen. En este sentido. lo dije antes. esta obra puede ser considerada como un documento precioso para estudiar la psicologia de Unamuno, cuya alma se nos presenta tras-

(1) Aquí se encuenfra la explicación de la actitud de Unamuno ante la Monarquia y el Gobierno. No se frata de saber si el Directorio ha tenido o no razón al desterrarlo, si gobiernos anteriores fuvieron o no razón para destituirlo del rectorado de la Universidad de Salamanca. Unamuno siente religiosamente, como los profefas de larael, que tiene una misión que cumplir, provocar la destrucción de la vieja España oligárquica para fundar una España nueva. Si no lo hubiesen desterrado habria seguido su campaña en forma implacable, luchando de polencia a pofencia, no de subordinado a superior, con el Directorio. El problema debe plantearse así fué infeligente o forpe para sus propios infereses la resolución del Directorio. No es un problema de legalidad sino de fáctica politica. La hisforia demuestra que siempre, a la larga, cuando han luchado el despofismo y los valores intelectuales, el triunfo ha correspondido a estos últimas aunque lo hayan alcanzodo después de la muerle de sus porfavoces. 
lúcida a través de páginas desbordantes de emoción. Esa tragedia es más terrible que la que se desarrolla en el alma de los místicos en sus crisis diabólicas. cuando se sienten perseguidos por la presencia de Satanás y atormentados por la ausencia de Dios. Más terrible que Satanás es la fría razón, siempre lúcida. cuando muestra con dolorosa imporfunidad que la verdad cordial es sólo ilusión afectiva.

La opinión de Unamuno está de acuerdo con la de Lange, el ilustre historiador del materialismo, y de Renán, que consideran la metafísica como una especic de poesía superior. algo que queda totalmente fuera de lo intelectual. algo que no tiene valor como conocimiento; pero va un poco más allá que estos pensadores porque sostiene que hay en las creencias fundadas en el sentimiento. cierta forma especial de conocimiento que conduce a una convicción inestable, no sobre lo que es sino sobre lo que aspira a ser, con lo cual toca muy de cerca las doctrinas de William James. Sin embargo Unamuno se allana a reconocer que este conocimiento intelectualmente carece de valor y lo distingue radicalmente del conocimiento científico. Su posición no coincide por lo tanto con la del pragmatismo: está mucho más cerca del ritschlianismo. Para Unamuno la verdad tiene diversas formas: la verdad moral, la verdad intelectual, la verdad estética, la verdad religiosa.

Lo admirable en la actitud de Unamuno, porque bien mirado su libro no es más que la justificación de su actitud ante ciertos problemas que considera irresolubles, lo que lo diferencia de los demás pensadores anti-intelectualistas, es su dualismo radical. Respeta a la ciencia positiva y pide que se le deje libre en el orden metafísico y religioso para construir una metafísica, una religión y una moral sobre la base del sentimiento de la inmortalidad. En la importancia que da al sentimiento no ha sido superado por nadie, y si su obra tiene alguna influencia de Ritschl. James o Bergson, hay que notar que estos se presentan siempre como pensadores. Abren en el muro de la razón una ventana para mirar al cielo. pero no abandonan su actitud de razonadores. Tratan siempre de llevarnos al convencimiento racional, aun de aquello que han observado a través de la ventana hecha en el muro de la razón, y aspiran a armonizar el conocimiento racional con el otro para alcanzar una sintesis armónica. un sistema.

Funda su convicción espiritualista sobre una base afectiva, porque no encuentra ninguna consistencia al espiritualismo intelectual. A la razón no le pide argumentos sino para probar que su posición no es absurda, y se allana a reconocer, y esto le interesa muy particularmente. que la posición contraria tiene mayor grado de posibilidad y es por consiguiente la más aceptable dentro del criferio científico. No le interesan los esfuerzos de un Bergson para establecer el máximum de probabilidades a lavor de la hipótesis dualista que distingue la materia y la conciencia como substancias diferentes, única posición filosófica que. para Unamuno. es capaz de salvar la creencia en la inmortalidad personal. En el orden cientifico es francamente materialista, mientras los demás filósofos antiintelectualistas aspiran a fundar una metafísica espiritualista en armonía con la ciencia. 
Unamuno establece que en el fondo de toda tendencia espiritualista hay un sentimiento impulsor que no es el amor desinteresado a la verdad, el ansia de inmortalidad. Prefiere fundar su creencia, no su conocimiento, únicamente sobre este sentimiento, y en contradicción, ya no inconsciente como se puede notar en otros filósofos. sino consciente o intencionalmente. con la convicción intelecfual a que lo habia llevado la ciencia positiva. Asi queda el mundo ideal de la creencia a cubierto de todo avance de la filosofía cientifica: el filósolo se ha colocado en la hipótesis extrema para afirmar desde alli con vigor afectivo y potencia volitiva, pero con creencia a base de incertidumbre, la le en Dios y en la inmortalidad, la fe en un Dios que se crea de continuo en la mente por la fe que en él se tiene, y una moral que, puesta en acción, es creadora y garantía de nuestra inmortalidad.

La filosofia de Unamuno es una filosolia personalisima, fundada en el análisis psicológico de la crisis religiosa de una conciencia católica que ha asimilado la ciencia positiva y sacado las últimas consecuencias del criterio científico.

Aunque parezca paradojal. Unamuno, el metafisico menos cientifico,- nadie ha desterrado como él el intelectualismo-. es el que está más cerca del positivismo. porque ninguno ha aceptado y reconocido con mayor respeto que él las conclusiones de la ciencia positiva y de sus hipótesis más extremas en el sentido opuesto a su metafísica. Puede objetarse que esta posición la consigue sólo Unamuno a costa de contradicción palmaria y confesada, pero ¿qué metafísico no cayó en contradicción? Con razonamientos abogadiles todos han tratado de disimular el ensamblamiento imperfecto de los diversos cuerpos de sus construcciones metafisicas. Son razonamientos consoladores y engañadores para discipulos con mucha fe en el maestro y poco espiritu de análisis, pronto descubiertos por la crítica, que ha dejado todos los monumentos de la metafísica racionalista, amenazando derrumbarse, con sus fallos a la vista de todos.

El pensador español, por el contrario, parte de la contradicción como de un hecho establecido sobre el cual se funda su estado sentimental. su sentimiento trágico, que da origen a la fe a base de incertidumbre en algo que no es. pero aspira a ser, algo que constantemente se crea. Lo que fué falla en otras consfrucciones metafisicas es en ésta fundamento.

La filosofia es para Unamuno un producto natural de la conciencia y aun de la vida toda. La fórmula ahondando en su propio yo, y al formularla siente que formula la filosofía de un pueblo, el español, del cual se cree intérprefe.

Agudeza critica y profundidad afectiva dan origen a esta actitud unamuniana que se llama su filosofia. Poca originalidad en las ideas-¿quién la tiene en filosofía? - pero actítud trágica, reconfortante y viril ante la vida.

Su moral puesta en acción significa la conquista heroica de la inmortalidad por la persecución de un fin social. Mi vida comprobará mi doctrina, dijo pragmáticamente en 1912, y su vida. desde los ataques a la realeza que provocaron su destitución del rectorado de la Universidad de Salamanca. ataques cuya finalidad es remover reciamente el alma española, es la comprobación pragmática de esa afirmación. Este poeta y filósolo y hombre de acción que tan fundidas tiene 
estas tres formas de humanidad superior, racionalista y mistico heterodoxo, hace pensar igualmente en los profetas de Israel y en los místicos españoles del siglo de oro.

Discutir racionalmente su doctrina sería cosa ociosa. El mismo es su más agudo crílico, y nadie comprende mejor que él lo inestable de su posición.

Las soluciones del problema de las relaciones entre la ciencia y la religión de Haeckel. Spencer y Comte, representan la subordinación absoluta de la religión a la ciencia. Las soluciones de Ritschl y James representan ensayos de armonización de la ciencia y la religión de modo que cada una conserva su autonomia completa, hechos por pensadores de mentalidad protestante. La última en el orden del tiempo. ésta de don Miguel de Unamuno, es un ensayo de acuerdo entre la ciencia y la religión sobre la base de su contradicción intima, por una mentalidad formada en un ambiente católico.

Unamuno. cristiano heterodoxo, anti-intelectualista, vitalista y pragmatista, al mismo tiempo que sabio dotado de un profundo espiritu cientifico, soñador y realista, poeta y hombre de acción, hombre contradictorio que funda en la gran contradicción entre lo real y lo ideal su fe y los motivos de su acción. es la figura más original y vigorosa de la España viva de hoy. y la figura profética de la España que vendrá, de la que actualmente se está engendrando.

ENRIOUE L. MARSHALL.

Concepción, 1924. 